\title{
Study on Characteristics and Logic of Procedures of Economic Law
}

\author{
Xiaoman Zhai \\ Chongqing University of Education, Chongqing, 400065, China
}

\author{
Keywords: Economic law. Procedure. Characteristics. Logic
}

\begin{abstract}
Economic Law indicates a kind of law that confirms and regulates government to reasonably intervene in economy. And the question of procedure in economic law has always been a problem that is easily ignored by researchers. It's a good research approach to probe into relevant problems of economic law through a perspective of procedures of economic law. Strengthening and perfecting procedures of economic law is one of the focuses of economic legislation in China. This paper elaborated main characteristics of procedures of economic law and emphasized the logical analysis on procedures of economic law.
\end{abstract}

\section{Introduction}

Rooted in tradition and transcended tradition, the modern economic law system not only extremely relied on administrative procedure and civil procedure in conventional sense but also transcended the tradition. The procedures of economic law have been equipped with characteristics such as rational instrumental value and informal procedures. And behind the above characteristics, there lies in internal logic of procedures of economic law. The procedures of economic law has equipped with the function of overcoming market failure just like entity systems. Therefore, further research should be carried out focusing on logics in procedures of economic law such as restriction of powers, democratic value and efficiency value, etc. to constantly complete the economic law system in China.

\section{Main characteristics of procedures of economic law}

\section{Rational instrumental value characteristic}

Start from the standard of value for satisfying social needs to divide the value goal of economic law into objective value and instrumental value. Thus it's undoubtedly equipped with rationality but it's not the only division way. Starting from the perspective of knowledge and based on pure rationality standard, the feature of economic law's value includes a sound logic within the law. It not only includes the analytical concept and logic of law but also manifests in coordination between entity law and procedural law. Therefore, actually the value system possessed by economic law should be provided with diversity. It is effective to take the evaluation criterion for procedures of economic law according to rational instrumental value, thus the value feature of legal procedure has been described as a method to achieve the optimal results. The proposition of instrumental principle of procedures of economic law is of great significance for both the development of market economy and legal system itself. As far as the development of market economy is considered, the restriction on randomness and guarantee of rational choice brought by the procedure can maintain the dependency on individual rationality when market economy just takes shape. At the same time, we should also apply procedures to guarantee the independent character of market relative to the nation. As far as legal system itself is considered, the principle of procedures of economic law lays the basis of legitimacy for a sound legal order establishing authority and respect of law through conducting substantial law. At the same time, procedural law and economic law have been equipped with the function to maintain independence of law and autonomy. At present, China is still at a preliminary stage of socialist market economy with Chinese characteristics and legal construction. As for economic law, the goal of sustainable development and procedural rationality are instrumental and part of the scope of instrumental value. Even if justice of results, economic security and efficiency of 
the system are considered, the rationality of procedures mainly serves for the justice of results, security of economy and efficiency of system. It also exists for protection of system. Therefore, one of the important characteristics of procedures of economic law is its rational instrumental value.

\section{Characteristic of informal procedure}

The difference between formal procedure and informal procedure lies in the legality and effective application of the procedure. As a general rule, formal procedure mainly indicates those with strict rules in laws and regulations and informal procedure mainly refers to those with relatively great flexibility in operation or conduction. The economic law emphasizes its characteristics as an informal procedure under most occasions. At the same time, in order to practically prevent the randomness during the application process of procedure and protect legal interest of participants of the procedure and interested party, which also reflect its characteristic as an informal procedure and its pursuit of fair value. However, justice itself is an abstract definition and it has relatively strong subjectivity and sometimes justice cannot be described but felt by each subject. Therefore, the guarantee of informal procedure for justice can only serve as a value expression as a greatest common divisor instead of truly realizing the goal of justice. And different subjects may have different perceptions, which require informal procedures of economic law lay emphasis on justice and absorb elements that have been universally accepted as elements that can guarantee justice into the operation of procedure.

\section{Logical analysis of procedures of economic law}

\section{Logic of restriction of powers}

Living in modern society, we must abide by idea of rule of law and the center of idea of rule of law is the supremacy of law. As for governmental powers, it means that the statistic governmental powers under rule of law shall be restricted by legal entity, which is also a boundary constraint. As for dynamic governmental powers, they must be subject to the restriction of legal procedure. Modern market economy requires government to be equipped with considerable economic power and it's quite necessary to put certain restriction on this power. It may seem contradictory but actually it is not. That's because rule of law lays emphasis on the center of controlling power therefore it doesn't have to restrict the power authorized by law from entity, instead, it requires that the governmental power must be rational rather than arbitrarily performed from procedures. The economic power of government must be included in rational procedures and procedural systems must be applied to prevent randomness and arbitraries during the execution of power. It has been a focus for the development of rule of law by people from all over the world. The concern for procedures of economic law in modern civilized society is largely derived from the need of restricting power and one of the important ways to restrict power is the overlapping and counterbalance of various powers. The central content of procedures of economic law is restricting economic power so as to design legal space and method for the operation of economic law, namely, determining the dependency of each subject of economic power. Under general conditions, the subject of economic law can be simply divided into regulating subject and controlled subject. Guaranteeing the participation rights of controlled subject mainly embodies the democratic value of procedures of economic law, while making clear the counterbalance and rules for different regulating subjects embodies the logic of power restriction in procedures of economic law. This value can be reflected by the universality possessed by regulating subjects of economic law. Government sectors are certainly the most important subject of procedures of economic law and they have very extensive functions in economic regulation and control. Although government sectors are regulating subjects that interfere economic at the earliest, there have been a diversified tendency in regulating subject due to the rational development of state macro-control practice.

\section{Logic of democratic value}

The government performs its economic power with the purpose to regulate the social economy as a whole. Because government has its own alignment of interests, it can easily result in abuse of power and impede the development of economy. Therefore, during the rational development of procedures of economic law, there have been a tendency of transformation from state-oriented to standard of 
society and economic law thus has become a measure to regulate government's economic behavior with social public interest as value orientation. And social public interest as an abstraction has to be put into practice in each economic subject. As for whether different economic subjects have enough right to speak for governments' economic behavior that concerning their own interests, the democracy of procedures of economic law also needs to be further studies. The most important manifestation of democracy of procedures of economic law lies in the participation right of relevant interest subject, which can be put their esteem and interests under good protection through legal procedures. In fact, the characteristics of market subject as economic man is an important cause that results in market failure. Therefore, it's necessary to have a power which can be independent in market and control the market and experienced in economic operation to conduct market regulation and control. However, it doesn't mean what the market economy needs is elite governing and market subjects have to acknowledge laws designed by experts. As far as procedures of economic law are considered, the participation has become an important value for the participation process itself. The reason for why some economic policies cannot be widely implemented merely lies in the lack of rationality in the economic policies and more probably, it may be because relevant interest subjects fail to participate in it so they ignore the existence of economic policies. All economic individuals desire to hear their own voice in economic life that closely related to their fate. The great attention put to legal procedure is an important symbol for humans entering civilized society. Far back in uncivilized area, people resorted to military force to solve various disputes, thus it's awash with suppression on the weak by the strong. In order to settle disputes, dominators often adopted compelling forces to put down them and gain relatively stable ruling order. As long as humans entered civilized area from uncivilized area, a whole set of democratic legal procedures gradually came into being, thus resolving military force into civilized and rational dialogue. And procedures of economic law are procedures presupposed by government sectors during regulating and controlling macroeconomic reform and development to implement various economic behaviors. Their democracy will require the government to adequately listen to opinions proposed by all interest subjects when making and introducing each economic policy and also requires the government to fully consider controlled parties' vital interests during the implementation of economic policies. During the democratic procedures of economic law, only when different even opposing parties' interest propositions and value pursuits are manifested and balanced can various dissatisfaction, doubts even conflicts be eliminated during this process so as to let disputes between various interest parties be properly settled and provide a good basis for the authority of the execution of economic power.

\section{Logic of efficiency value}

The socialist market economy with Chinese characteristics cannot do without planning and the making and implementation of plan is bound to surpass the authority of market. This authority mainly derives from the government, since market economy in all kinds needs governmental support and they also have to support the government. Especially in the market economy system of developing countries, government sectors have possessed indispensable functions. However, the government which has possessed authority cannot solely depend on the compelling force carried out by the country. The general compliance with law cannot only depend of the sanction made by the government. Only when the country and law can reflect the common aspiration and general interest of the society to some extent and when they have been approved by people can they have a more adequate effect. Especially during the transitional period for Chinese economy, the incomplete legal system, overcomplicated economic reality, constantly widening gap between the rich and the poor, frequent happening of phenomena of social injustice make modern people have doubts and uncertainties in their mind. And this will result in a situation that economic decisions made by the government which are closely related to people's life fail to be generally approved by people, which will also affect the efficiency for government to make decisions. In this way, market is badly in need of guidance and regulation on the one hand, and on the other hand, he orders cannot be executed and prohibitions cannot be abided by. Therefore, the acknowledgement of authority will surely be transformed into problems about justice to be addressed. As long as a unitive ideology exists in a 
society, legal procedures will lose their significance. That's because generally the value of unitive ideology doesn't need to be argued and proved let alone conducting selective interpretation. As long as the unified state of value has gone, legal procedures will suddenly become an important supporting point of value. Some western politics scholars also proposed that nowadays in western developed countries, the loss of natural law can also be compensated by procedural law. Thus it's clear that in contemporary society which is short of belief in natural law, in order to establish legal order, the authority of law will relay more on the rationality and justice of procedural law. Authority derives from assurance and acknowledgement. As far as modern people who have possessed rationality are considered, assurance is determined through the process of demonstration, which means before obeying a decision, the parties involved will consider the legitimation basis for conducting this decision. This basis indicates the satisfaction of procedural qualifications. Because in just procedures of economic law, proposition and objection proposed by parties involved can be adequately expressed, their value or interest at different level in their competition can be comprehensively considered and weighed, thus the consequence will be dissolving of their dissatisfaction by this process. Comparatively speaking, the reason for why the most reasonable explanation and judgment will be adopted at last is also because decisions made in this way can diminish the space for suspect and protest after the event to a large extent. In this way, the decision which applies legitimate procedures of economic law can be truly executed.

\section{Conclusion}

Generally speaking, the content of entity of economic law often possesses great uncertainties. The limited rationality possessed by human cannot only made us at a loss what to do when dealing with many economic problems but also let us feel overwhelmed by the future with constant changes at any time, thus resulting in content of entity of economic law failing to better reflect economic laws and as a result, the efficient state in economics cannot be achieved. While economic law possesses characteristics such as rational instrumental value and informal procedures to guarantee the active participation right of each economic individual to transform those substantial issues that cannot be solved into a matter of procedure and absorb economic individual into a procedure which has both justice and rationality to conduct communication or compromise, which cannot only avoid possible dissatisfaction in the society because the content of entity cannot be mastered and also let the results of entity be widely accepted and implemented to realize another efficient state. Therefore, it can be more widely accepted and implemented.

\section{References}

[1] Liu Jin: Preliminary Probe into Procedural Problems in Economic Law, Political Science and Law, $2002(2)$

[2] Jiao Haitao: The Dual Structure of Economic Law Procedures and Its Imbalance, Northern Legal Science, 2007 (6)

[3] Wu Huasheng: Humble Opinions on Intrinsic Value of Procedures of Economic Law, Nanfang Lunkan, 2009 (5)

[4] Zhou Man: Reflection on Construction and Improvement of Procedural System to Overcome Uncertainties in Economic Law, Social Science Front, 2011 (2)

[5] Li Yexin: Discussion on Risks of Substantiation of Economic Law and Solutions by Procedural Law, Legal And Economic, 2012 (5) 